\title{
La jurisdicción constitucional en Guatemala
}

\author{
Por Francisco Fernández Segado
}

\section{Control de la constitucionalidad de las leyes}

\section{Antecedentes históricos y ordenación normativa actual}

El 24 de julio de 1823 se reunía en la ciudad de Guatemala un Congreso Nacional integrado por 64 diputados y presidido por el presbítero don José Matías Delgado, natural de San Salvador, que el 2 de julio siguiente adoptaba la denominación de Asamblea Nacional Constituyente. Tras diecinueve meses de ardua labor, la Asamblea clausuraría sus sesiones el 23 de enero de 1825 tras promulgar un importante conjunto de leyes ${ }^{1}$ y, especialmente, la Constitución Federal de la República de Centro-América de 22 de noviembre de $1824^{2}$.

Como recuerda García Laguardia ${ }^{3}$, en la fundación de la República, la fuente norteamericana aparece clara en el primer constituyente federal de 1824. Y en ese influjo ha de incluirse la de idea del control judicial de la constitucionalidad, familiar a los constituyentes, si bien no quedó finalmente reflejada en la citada Constitución.

Sin embargo, las Reformas de 1835 a la Constitución Federal de 1824, sí que acogerían en su art ${ }^{0} 189$ una cláusula ${ }^{4}$ muy similar a la cláusula de supremacía de la Constitución norteamericana de 1787. En efecto, a tenor des $\operatorname{art}^{\underline{0}} 189$ tras la nueva redacción dada al mismo en 1835:

"Esta Constitución y las leyes federales que se hagan en virtud de ella; y todos los tratados, hechos o que se hicieren bajo la autoridad federal, serán la suprema ley de la República, y los jueces en cada uno de los Estados, están obligados a determinar

Pueden versa tales normas legales en Ricardo Gallardo, Las Constituciones de la República Federal de Centro-América", vol. III, Instituto de Estudios Políticos, Madrid, 1958, págs. 661 y sigs.

2

Su texto, en Ricardo Gallardo, Las Constituciones..., op. cit., págs. 703 y sigs.

3 Jorge Mario García Laguardia, La defensa de la Constitución, Facultad de Ciencias Jurídicas y Sociales (Universidad de San Carlos de Guatemala), Instituto de Investigaciones Jurídicas de la UNAM, Guatemala - México, 1986, pág. 52.

4 Las Reformas de 1835 pueden verse en Ricardo Gallardo, Las Constituciones..., op. cit., págs. 739 y sigs. 
por ellas, no obstante cualesquiera leyes, decretos u órdenes que haya en contrario en cuaquiera de los Estados."

La cláusula que acabames de transcirbir no iba a dejar de incidir a nivel legislativo ordinario en Guatemala. En efecto, la asamblea Legislativa del Estado de Guatemala, el más importante de la Federación, promulgaba el 13 de septiembre de 1837 la "Déclaración de los derechos y Garantías que pertenecen a todos los ciudadanos habitantes del Estado de Guatemala" ${ }^{5}$, cuyo $\operatorname{art}^{\stackrel{0}{0} 5^{\mathfrak{}}}$ prescribía lo que sigue:

"Que toda determinación sea en forma de ley, decreto, providencia, sentencia. auto $\mathrm{u}$ orden que proceda de cualquier poder, si ataca alguno o algunos de los derechos naturales del hombre, o de la comunidad, o cualquiera de las garantías consignadas en la ley fundamental, es ipso iure nula, y ninguno tiene obligación de acatarla y obedecerla."

Un año más tarde, en 1838, inicio de la ruptura de la Federación, la misma Asamblea Legislativa promulgaba un Decreto de cuatro artículos que venía a desarrollar esa idea de la supremacía constitucional. Ninguna ley contraria a la Constitución, prescribía su $\operatorname{art}^{\underline{\varrho}} 1^{\varrho}$, puede ni debe subsistir. Y el art ${ }^{\stackrel{0}{2}}{ }^{\varrho}$ disponía que cuando se presenta alguna notoriamente contraria a la Constitución, "los tribunales deberán arreglarse en sus juicios al sentido claro de la fundamental, informando en seguida al cuerpo legislativo". Cuando se presentaren casos dudosos, "los tribunales y cualquier ciudadano pueden pedir a la asamblea la declaratoria correspondiente, sin perjuicio de que dichos tribunales resuelvan desde luego, según entiendan en justicia, y por su propio convencimiento". La declaratoria del cuerpo legislativo sólo podía aplicarse a los casos posteriores al que motivó la duda, no pudiendo tener jamás un efecto retroactivo.

Como puede apreciarse, Guatemala instauraba a través de esta vía un control jurisdiccional de la constitucionalidad, matizado por la intervención del cuerpo legislativo. Sin embargo, a la caída del régimen liberal, coincidente con la quiebra de la Federación, la idea fue abandonada. Como señala García Laguardia ${ }^{6}$, los gobiernos de la restauración conservadora desconfiaban de la revisión judicial, lo que explica el Decreto de 27 de septiembre de 1845 que, de modo explícito, determina la necesaria inhibición por los tribunales del conocimiento de los actos de los poderes Legislativo y Ejecutivo. "Ningún acto del Poder Legislativo ni Ejecutivo - determina tajantamente el $\operatorname{art}^{\varrho} 1^{\varrho}$ del citado Decreto - está sujeto a la

Puede verse el texto de la Declaración en Jorge Mario García Laguardia, La defensa de la Constitución, op. cit., págs. 83-86.

Jorge Mario García Laguardia, La Corte de Constitucionalidad (Tribunal Constitucional) de Guatemala. Orígenes y Competencias, en Cuadernos Constitucionales México-Centroamérica, $\mathrm{n}^{\mathrm{Q}} 8$ (Instituto de Investigaciones Jurídicas de la UNAM - Corte de Constitucionalidad de la República de Guatemala), México, 1994, págs. 29 y sigs.; en concreto, pág. 32. 
revisión de los tribunales de justicia, los cuales no pueden conocer de la nulidad o injusticia que aquéllos contengan."

La reforma liberal de la década de los setenta ${ }^{7}$, reflejos de la cual serían las Asambleas Constituyentes de 1872 y 1876, plasmaría en la Constitución de 1879, la de mayor permanencia de la historia guatemalteca, que, asentada en una concepción rigidísima del principio de la división de poderes, ignoró toda referencia al control de la constitucionalidad. Habría que esperar a las reformas introducidas en aquella Constitución el año 1921 para ver entronizado al máximo rango jurídico el control jurisdiccional de la constitucionalidad de las leyes.

En efecto, el inciso c/ del $\operatorname{art}^{\circ}$ 93, tras la redacción dada al mismo en 1921, establecía que "dentro de la potestad de administrar justicia, corresponde al Poder judicial declarar la inaplicación de cualquier ley o disposición de los otros poderes cuando fuere contraria a los preceptos contenidos en la Constitución de la República, pero de esta facultad sólo podrán hacer uso en las sentencias que pronuncie".

Las reformas inmediatamente antes referidas de marzo de 1921 daban paso a la Constitución Federal de septiembre del mismo año 1921, que no sólo mantenía en lo básico el precepto anterior, sino que adicionaba (en su art $^{\circ} 130$ ) la posibilidad de establecer ante la Corte Suprema de Justicia Federal un recurso de inconstitucionalidad de una ley que se refiera a asuntos no ventilados ante los tribunales, recurso para el que quedaría legitimada toda persona a quien dicha norma legal perjudicara en sus legítimos derechos, por su aplicación en un caso concreto.

La nueva modificación constitucional de diciembre de 1927 acogía de modo expreso la previsión de que ninguna ley podía contrariar las disposiciones de la Constitución, habilitando tanto a la Corte Suprema de Justicia como a los Tribunales de segunda instancia y a los jueces letrados que conozcan en la primera, declarar la inaplicación de cualquier ley o disposición de los otros poderes cuando fueren contrarias a los preceptos contenidos en la Constitución de la República, in aplicación que tan sólo podía ser declarada en los casos concretos de que conocieran dichos órganos jurisdiccionales y a través de las resoluciones que los mismos dictaran.

La Constitución de 1945 mantuvo la línea emprendida un cuarto de siglo antes, habilitando a los tribunales de la jurisdicción ordinaria y al de lo contencioso administrativo para declarar en casos concretos y por sentencia de primera, segunda instancia y casación, la inaplicación de cualquier ley o disposición de los organismos que ejerzan las demás funsitaria de Guatemala, Guatemala, 1985. 
ciones del poder público, cuando fueran contrarias a la Constitución. La Constitución que nos ocupa suscitó una nueva problemática, como bien advierte García Laguardia la del control de oficio de la constitucionalidad, que derivaba de la determinación del primer inciso de su $\operatorname{art}^{0} 50$, de conformidad con el cual, las disposiciones legales, gubernativas o de cualquier otro orden que regulen el ejercicio de los derechos que la Constitución garantiza, "serán nulas ipso iure si los disminuyen, restringen o tergiversan", norma que se complementaba con otra que declaraba asimismo la nulidad ipso iure de los actos o contratos que violaran las normas constitucionales. A grandes rasgos, estas previsiones normativas se mantendrían en la Constitución de 1956.

Sería, no obstante, la Constitución de 15 de septiembre de 1965, la que introduciría un sesgo radicalmente novedoso en cuanto atañe al control de la constitucionalidad, al establecer un sistema mixto que conjugaba la tradición del control judicial difuso norteamericano con la instauración de una Corte de Constitucionalidad que asumía un control de la constitucionalidad en vía principal con una declaratoria de inconstitucionalidad con efectos generales.

La Carta de 1965 consagra de modo insquívoco la supremacía constitucional al disponer que los tribunales de justicia habían de observar siempre el principio de que la Constitución prevalece sobre cualquier ley o tratado internacional, norma que se complementaba con la declaración de nulidad ipso iure de las leyes o disposiciones de cualquier orden que, de un lado, violaran o tergiversaran los mandatos constitucionales, y de otro, regularan el ejercicio de los derechos constitucionalmente garantizados, disminuyéndolos, restringiéndolos o tergiversándolos.

El $\operatorname{art}^{\complement} 246$, al enumerar las atribuciones generales del Poder Jucial, acogía el control difuso e incidental, al prever que en casos concretos, en cualquier instancia y en casación., antes de dictar sentencia, las partes podrían plantear la inconstitucionalidad total o parcial de una ley, debiendo el tribunal pronunciarse al respecto, en el bien entendido de que si se declarare la inconstitucionalidad, la sentencia había de limitarse a establecer que el precepto legal era inaplicable al caso planteado, siendo transcrito dicho precepto al Congreso. El Decreto núm. 8 de la Asamblea Nacional Constituyente desarrollaría tales determinaciones, estableciendo dos vías procedimentales: la vía de acción y a de excepción. La sentencia admitiendo la inconstitucionalidad era declarativa, esto es, establecía una nulidad preexistende con efectos retroactivos (ex tunc), generando efectos tan sólo respecto del caso concreto en que fuere dictada ("inter partes").

9 Cfr. al efecto el detenido comentario y desarrollo de Jorge Mario García Laguardia, La defensa de la Constitución, op. cit., págs. 55-79. 
Junto al anterior modelo de control, la Constitución de 1965 acogía un control concentrado, principal (no incidental) y de efectos "erga omnes". Este control se encomendaba a un tribunal no permanente, sino que se integraba cuando se presentaba una acción: La Corte de Constitucionalidad.

La Corte de Constitucionalidad quedaba integrada por doce miembros, cuatro de ellos designados por la Corte Suprema de Justicia y los restantes por sorteo realizado por la propia Corte Suprema, entre magistrados de la Corte de Apelaciones y del Tribunal de lo Contencioso Administrativo. La Corte de Constitucionalidad era presidida por el propio Presidente de la Corte Suprema.

La acción de inconstitucionalidad de que conocía esta Corte de nueva creación tenía por objeto obtener la declaratoria de inconstitucionalidad de las leyes o disposiciones gubernamentales de carácter general viciados total o parcialmente de inconstitucionalidad.

Se hallaban legitimados para plantear una acción de esta naturaleza: el Consejo de Estado, órgano que presidía el Vicepresidente de la República; el Colegio de Abogados, por decisión de su Asemblea general; el Ministerio Público, por disposición del Presidente tomada en Consejo de Ministros, y cualquier persona o entidad a quien afecte directamente la inconstitucionalidad de la ley o disposición gubernativa impugnada, con el auxilio de diez abogados.

El Ministerio Público era siempre parte, correspondiéndole la legitimación pasiva, viniendo obligado a realizar la defensa de la constitucionalidad de la norma impugnada, bien que pudiera asimismo mostrarse de acuerdo con la impugnación.

La sentencia estimatoria de la inconstitucionalidad requería del voto favorable de ocho de los doce miembros de la Corte, pudiendo declarar la inconstitucionalidad total o parcial de la ley o norma de carácter general impugnada.

Fix-Zamudio ${ }^{10}$, con evidente razón, se manifestaría críticamente tanto ante este elevado quorum de votos necesarios para la declaratoria de inconstitucionalidad como frente a esa exigencia del auxilio impresionante de un verdadero ejército de abogados (nada menos que diez) cuando la legitimación se refiere a los particulares afectados, no pudiéndose olvidar tampoco que en el caso de ser declarado sin lugar un recurso interpuesto por una persona o entidad afectada por la supuesta inconstitucionalidad, la norma reglamentaria de desarrollo preveía una multa a cada uno de los abogados auxiliantes, además de la condena en costas al recurrente.

10

Héctor Fix-Zamudio, Los Tribunales Constitucionales y los derechos humanos, Instituto de Investigaciones Jurídicas, UNAM, México, 1980, págs. 141-142. 
El Tribunal, que se integraba para conocer de cada acción, al no tratarse de un órgano permanente, había de pronunciarse sobre la suspensión provisional de la norma recurrida, medida cautelar que procedía si la inconstitucionalidad fuere notoria y susceptible de causar gravámenes irreparables, y que debía ser dictada con el voto favorable de la mayoría del total de miembros de la Corte, suspensión que tenía efectos generales.

La sentencia dictada por el Tribunal tendría efectos, según García Laguardia ${ }^{11}$, semiconstitutivos, calificación que respondía al hecho de que en el caso de que decretara la suspensión provisional, sus efectos eran "ex tunc", pues venía a establecer una suerte de nulidad preexistente en forma retroactiva, mientras que en los demás casos la sentencia era constitutiva, siendo sus efectos "ex nunc".

La experiencia de la Corte guatemalteca fue corta, como la de la propia Carta de 1965: de 1966 a 1981, escasamente quince años, pero, según una vez más García Laguardia ${ }^{12}$, fue fructífera. En ese lapso, conoció de muy pocos casos. El Consejo de Estado y el Colegio de Abogados no hicieron uso de su legitimidad para accionar ante la Corte; el Presidente de la República lo hizo una sola vez (por cierto, el único recurso estimado por la Corte mediante Sentencia de 8 de enero de 1971, por la que la Corte de Constitucionalidad falló declarando la inconstitucionalidad del Decreto núm. 1725 del Congreso de la República) y los demás recursos fueron interpuestos por particulares. La experiencia vino, por lo demás, a demostrar que el peligro del "gobierno de los jueces", o lo que es igual, de la politización del Tribunal, no se evidenció. Una vez más según el gran jurista guatemalteco ${ }^{13}$, las causas fundamentales por las cuales la actividad del órgano en cuestión satisficieron las expectativas sobre su papel fueron: la integración específicamente judicial de sus miembros, su carácter de tribunal circunstancial y la legitimación restringida para su actuación.

El golpe de Estado de 23 de marzo de 1982 declaró en suspenso la Constitución de 1965. Tras una corta etapa, regida por un Estatuto Fundamental del Gobierno, se iniciaba, bajo la tutela castrense, un nuevo proceso de transición hacia la democracia que culminaba en las elecciones constituyentes celebradas el 1 de julio de 1984, de resultas de las cuales se constituyó una Asamblea Constituyente con una representación muy plural de todas las fuerzas políticas, circunstancia que obligó a la transacción permanente, culminando el proceso constituyente el 31 de mayo de 1985, con la promulgación de la nueva Constitución noy vigente en el país. 
Ya en unas Jornadas constitucionales organizadas por el Colegio de Abogados de Guatemala con vistas a enriquecer el debate constituyente y en un documento elaborado por encargo de la Universidad Nacional, que se entregó a la Asamblea Constituyente en su instalación $^{14}$, se sugirió la idea de que se avanzara en la conformación de un sistema de garantía más efectivo, aprovechando la amplia experiencia del funcionamiento de la Corte de Constitucionalidad, transformándola en un tribunal permanente y ampliando su competencia.

La nueva Constitución, promulgada, como ya dijimos, el 31 de mayo de 1985, que entró en vigencia el 14 de enero de 1986, dedica su Título IV a las "garantías constitucionales y defensa del orden constitucional" (artículos 263 a 276), configurando un nuevo sistema cuyo rasgo más novedoso es la creación de la Corte de Constitucionalidad como órgano permanente. Digamos finalmente que, en desarrollo de la previsión constitucional del $\operatorname{art}^{\underline{ }}$ 276, la Ley constitucional de amparo, exhibición personal y de constitucionalidad de 1986 ha venido a desarrollar el referido Título de la Constitución.

\section{Tipo de control}

La Constitución guatemalteca de 1985 combina el modelo de control de constitucionalidad en el caso concreto, en la tradición del control judicial difuso norteamericano, con el modelo de control abstracto y concentrado, siguiendo con ello muy de cerca las pautas trazadas en 1965.

En efecto, a tenor del $\operatorname{art}^{\underline{0}} 204$ de la Norma suprema, "los tribunales de justicia en toda resolución o sentencia observarán obligadamente el principio de que la Constitución de la República prevalece sobre cualquier ley o tratado". En lógica armonía con la previsión inmediatamente anterior, el $\operatorname{art}^{\circ} 266$ contempla de modo específico la inconstitucionalidad de las leyes en casos concretos. De conformidad con el mismo, en casos concretos, en todo proceso de cualquier competencia o jurisdicción, en cualquier instancia y en casación y hasta antes de dictarse sentencia, las partes podrán plantear como acción, excepción o incidente, la inconstitucionalidad total o parcial de una ley. El tribunal deberá pronunciarse al respecto.

Junto a ese control concreto, el art ${ }^{0} 267$ de la Constitución se refiere de modo particularizado al control abstracto o de carácter general, al determinar que: "Las acciones en contra de leyes, reglamentos o disposiciones de carácter general que contengan vicio parcial o

14

Puede verse este documento, obra sustancialmente del García Laguardia, en Jorge Mario García Laguardia, La Corte de Constitucionalidad..., op. cit., págs. 39-41. 
total de inconstitucionalidad, se plantearán directamente ante el Tribunal o Corte de Constitucionalidad."

A su vez, dentro del control abstracto nos encontramos con dos modalidades diferenciadas: el control represivo mediante la acción de inconstitucionalidad, del que nos ocuparemos más adelante, y el control preventivo, cuyo rasgo más peculiar es el carácter no vinculante de la opinión consultiva emitida por la Corte de Constitucionalidad, órgano competente al efecto. Nos detendremos brevemente en esta modalidad de control.

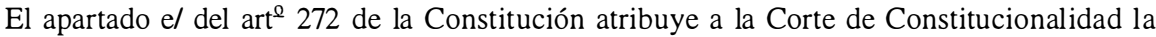
función de "emitir opinión sobre la constitucionalidad de los tratados, convenios y proyectos de ley, a solicitud de cualquiera de los organismos del Estado", provisión que reproduce el $\operatorname{art}^{2} 163$ de la Ley de amparo, exhibición personal y constitucionalidad (en adelante LAEC). Esta competencia es desarrollada por el Capítulo quinto del Título V de la misma Ley, que se refiere a las "Opiniones consultivas". La emisión de estas opiniones puede ser solicitada o requerida por el Congreso de la República, el Presidente de la República y la Corte Suprema de Justicia. El dictamen de la Corte de Constitucionalidad, que se califica como "opinión consultiva", parece diseñarse como algo diferenciado de las "decisiones" de la Corte, que, a tenor del $\operatorname{art}^{\underline{0}} 185$ de la LAEC, "vinculan al poder público y órganos del Estado". Bien es verdad que, como se ha precisado ${ }^{15}$, en todo caso, y pese a esa denominación de "opinión", no parece probable que el dictamen emitido por la Corte sea meramente consultivo y que el órgano requirente pueda discrepar de él; la fuerza vinculante de la opinión de la Corte parece evidente.

\section{Normas objeto de control}

Entre las tres modalidades que puede revestir el objeto del control (control de normas con rango de ley; control de todo tipo de normas de carácter general, y control de normas y de actos jurídicos no normativos), la Constitución de Guatemala ha optado, en lo que al control abstrato represivo se refiere, por el control de todo tipo de normas generales, sean de rango legal o reglamentario. Y así, el $\operatorname{art}^{\complement} 267$ de la Norma suprema alude a las acciones en contra de "leyes, reglamentos o disposiciones de carácter general", mientras que el $\operatorname{art}^{\mathrm{Q}}$ 272, en su apartado a/, atribuye a la Corte de Constitucionalidad la competencia para conocer en única instancia de las impugnaciones interpuestas contra "leyes o disposiciones de carácter general".

15

Luis López. Guerra, Protección de los derechos fundamentales por la jurisdicción constitucional en Centroamérica y Panamá, en el colectivo, Justicia Constitucional Comparada, Universidad Nacional Autónoma de México, México, 1993, págs. 67 y sigs.; en concreto, pág. 79. 


\section{Tribunales encargados del control y posibles instancias}

La Constitución de 1985, en la línea emprendida por la de 1965, crea una Corte de Constitucionalidad como "tribunal permanente de jurisdicción privativa, cuya función esencial es la defensa del orden constitucional" ( $\operatorname{art}^{\underline{0}}$ 268). Como se ha destacado ${ }^{16}$, uno de los rasgos en verdad peculiares del diseño constitucional de la Corte es la fortísima voluntad de independencia de la misma que muestra con su ordenación el constituyente guatemalteco. En efecto, no sólo se concibe el Tribunal como un órgano permanente al que se dota de una jurisdicción calificada de privativa, sino que se señala, adicionalmente, que "actúa como tribunal colegiado con independencia de los demás órganos del Estado", ejerciendo las functiones específicas que le asigna la Constitución y la ley de la materia, esto es, la Ley de Amparo, Exhibición Personal y de Constitucionalidad, aprobada por Decreto emitido por la Asamblea Nacional Constituyente (Decreto núm. 1/1986).

A salvaguardar esa independencia se encamina la independencia económica que la propia Constitución proclama ( $\operatorname{art}^{\circ} 268$, párrafo segundo), y que habrá de ser garantizada con un porcentaje de los ingresos que correspondan al Organismo judicial. La LAEC dispone al efecto que se asignará a la Corte una cantidad no menor del 5 por 100 del mínimo del 2 por 100 del presupuesto de ingresos del Estado que correspondan al Organismo judicial, cantidad que deberá entregarse a la Tesorería de la Corte cada mes en forma proporcional y anticipada por el órgano que corresponda. La misma Ley reconoce la potestad de la Corte para formular su propio presupuesto y administrar e invertir los fondos privativos, que son todos aquellos que se derivan de la administración de la justicia constitucional, fondo donde han de ingresar las multas que se impongan con motivo de la aplicación de la ley de la materia.

La integración de la Corte trata de ser coherente con esa pretensión de conformar un órgano realmente independiente de los demás órganos del Estado. La Corte se integra con cinco magistrados titulares, cada uno de los cuales tendrá su respectivo suplente. Ese número se eleva a siete cuando conozca de asuntos de inconstitucionalidad en contra de la corte Suprema de Justicia, el Congreso de la República, el Presidente o el Vicepresidente de la República; los dos nuevos magistrados se escogerán por sorteo de entre los cinco suplentes.

Los magistrados son elegidos de la siguiente forma: a/ un magistrado por el pleno de la Corte Suprema de Justicia; b/ un magistrado por el Presidente de la República en Consejo de Ministros; c/ un magistrado por el Consejo Superior Universitario de la Universidad de

Manuel Martínez Sospedra, El Tribunal Constitucional en la estructura del Estado. El caso de la Corte Constitucional de Guatemala, en Revista Jalisciense, año 5, núm. 3, septiembre de 1995 (Departamento de Estudios e Investigaciones de la Universidad de Guadalajara, México), págs. 29 y sig.; en concreto, pág. 50. 
San Carlos de Guatemala; d/ un magistrado por el pleno del Congreso de la República, y e/ un magsitrado por la Asamblea del Colegio de Abogados.

Como puede observarse, cada uno de los cinco integrantes de la Corte tiene una extracción independiente: mientras dos de los magistrados provienen de órganos de naturaleza política, un tercero es designado por el órgano que ejerce la suprema función jurisdiccional, esto es, la Corte Suprema de Justicia, mientras que los dos restantes son designados por instancias más bien técnicas: la Universidad de San Carlos y el Colegio de Abogados. La integración resulta, pues, notablemente equilibrada.

Los magistrados son elegidos por un período de cinco años, pudiendo ser reelectos por el organismo que los designó o por cualesquiera otros de los que tienen esa potestad de designación.

Simultáneamente con la designación del titular, se hará la del respectivo suplente, ante el Congreso de la República. La instalación de la Corte de Constitucionalidad se hará efectiva noventa días después que la del Congreso de la República.

Quizá sea un tanto exagerado afirmar, como algún sector de la doctrina ha hecho ${ }^{17}$, que el mejor sistema de integración en garantía de la imparcialidad y apoliticidad de un órgano de esta naturaleza es el de la Corte de Constitucionalidad de Guatemala, entre otras razones, porque no hay sistemas perfectos en abstracto, esto es, al margen de la específica realidad de cada país, si bien no cabe la menor duda, como antes dijimos, de que estamos ante una composición muy equilibrada.

La Constitución no fijó requisitos específicos, esto es, orientados a garantizar una determinada cualificación de quienes hubieren de acceder a la Corte, limitándose a exigir para ser magistrado de la Corte: a/ ser guatemalteco; b/ ser abogado colegiado; c/ ser de reconocida honorabilidad, y d/tener por lo menos quince años de graduación profesional. Complementariamente, el art $^{\underline{0}} 152$ de la LAEC, además de los requisitos contemplados por la Constitución, comunes a todos los magistrados, exige que éstos sean excogidos preferentemente entre personas con experiencia en la función y administración pública, magistraturas, ejercicio profesional y docencia universitaria, según sea el órgano que los designe.

Por lo que a su estatuto jurídico se refiere, el $\operatorname{art}^{\circledR} 270$ de la Constitución, en su último párrafo, dispone que los magistrados de la Corte de Constitucionalidad gozarán de la mismas prerrogativas e inmunidades que los magistrados de la Corte Suprema de Justicia. gados de Guatemala, n 32, julio-diciembre 1990, págs. 7 y sigs; en concreto, pág. 11 . 
La Presidencia de la corte será desempeñada por los magistrados titulares que la integran, en forma rotativa, en período de un año, comenzando por el de mayor edad y siguiendo en orden descendente de edades. la LAEC ( $\left.\operatorname{art}^{\underline{0}} 159\right)$ establecía que en la primera sesión que la Corte celebrara después de haber sido integrada, juramentada e instalada, prodedería a designar al Presidente y a establecer el orden de los magistrados conforme a su derecho de asunción a la Presidencia.

Al Presidente le corresponde la representación legal de la Corte y la selección, nombramiento y remoción del personal, siendo asimismo de su competencia la adopción de las medidas necesarias para su buen funcionamiento y el ejercicio de las potestades administrativas. Le corresponde de igual forma convocar y presidir la Corte para las sesiones, audiencias, vistas públicas y demás actos.

Son causas de cese del Presidente o de los magistrados: a/ verse afectado por un auto de prisión; b/ ser nombrado para cualquier cargo o empleo de la Administración del Estado, y c/ acceder a un cargo de dirección de un partido político o sindicato.

Por otra parte, como recuerda Barillas $^{18}$, ha de tenerse presente que el art ${ }^{\mathrm{Q}} 112$ de la Constitución establece a modo de disposición general que ninguna persona puede desempeñar más de un empleo, con excepción de quienes presten servicios en centros docentes; a su vez, el $\operatorname{art}^{\underline{0}} 207$ preceptúa que la función de Magistrado o Juez es incompatible con "cualquier otro empleo", por lo que si un magistrado de la Corte de Constitucionalidad se encontrara en ese supuesto, la misma Corte habría de conocer y resolver sobre la suspensión del magistrado en el ejercicio de su función.

En cuanto a las competencias de la Corte de Constitucionalidad, es preciso señalar que están específicamente enumeradas por el art $^{\circ} 272$ de la Carta suprema, que las amplía de modo significativo en relación a la experiencia inmediatamente anterior, propiciada por la Constitución de 1965.

Antes de referirnos en detalle a ellas, quizá convenga recordar con Gonzáles Rodas ${ }^{19}$ que la función esencial de la Corte es la defensa del orden constitucional, lo que equivale a decir que es garante o defensor de la Constitución y supremo intérprete de la misma. Sus funciones la lleva a cabo por la vía jurisdiccional, como Tribunal que es, a través del ejercicio de la jurisdicción constitucional, salvo los casos de consultas y dictámenes. de Guatemala, $\mathrm{n}^{\mathrm{O}}$ 32, julio-diciembre 1990, págs. 39 y sigs.; en concreto, pág. 45.

19 Adolfo Gonzáles Rodas, La Corte de Constitucionalidad de Guatemala, en Cuadernos Constitucionales México-Centroamérica, Universidad Nacional Autónoma de México - Corte de Constitucionalidad de Guatemala, México, 1992, pág. 14. 
Diferenciaremos en cuatro grandes bloques las atribuciones de la Corte de Constitucionalidad.

a) Como Tribunal de única instancia le corresponde:

1/ Conocer de las impugnaciones interpuestas contra leyes o disposiviones de carácter general, objetadas total o parcialmente de inconstitucionalidad ( $\operatorname{art}^{\mathrm{0}}$ 272, a/ de la Constitución de Guatemala - CG -).

2/ Conocer de los asuntos de inconstitucionalidad en contra de la Corte Suprema de Justicia, el Congreso de la República, el Presidente o el Vicepresidente de la República (art ${ }^{\stackrel{9}{ }}$ 269 CG).

3/ Conocer en calidad de Tribunal Extraordinario de Amparo en las acciones de amparo interpuestas en contra del Congreso de la República, la Corte Suprema de Justicia, el Presidente y el Vicepresidente de la República ( $\operatorname{art}^{\stackrel{0}{2}} 272$, b/ CG).

4/ Conocer y resolver lo relativo a cualquier conflicto de jurisdicción en materia de constitucionalidad $\left(\operatorname{art}^{\circ} 272, \mathrm{f} / \mathrm{CG}\right)$.

5/ Resolver los recursos de queja, cuando en el trámite del amparo no se cumple lo previsto en la ley o resuelto en la sentencia ( $\operatorname{art}^{\underline{0}} 72$ LAEC).

6/ Determinar la competencia cuando la misma no estuviere claramente establecida en asuntos de amparo ( $\operatorname{art}^{\circ} 15$ LAEC).

7/ Conocer y resolver los recursos de hecho, cuando se denegare la apelación, siendo legalmente procedente ( $\operatorname{art}^{\circ} 132$ LAEC).

8/ Conocer de las cuestiones de competencia entre los organismos y entidades autónomas del Estado ( $\operatorname{art}^{ } 164$ LAEC).

b) Como Tribunal de segunda instancia corresponde a la Corte:

1/ Conocer en apelación de todos los amparos interpuestos ante cualquiera de los Tribunales de justicia. Si la apelación fuere en contra de una resolución de amparo de la Corte Suprema de Justicia, la Corte de Constitucionalidad se ampliará con dos vocales, tal y como ya tuvimos oportunidad de señalar $\left(\operatorname{art}^{\underline{0}} 272, \mathrm{c} / \mathrm{CG}\right.$ en conexión con el $\operatorname{art}^{\stackrel{\varrho}{ }}$ 269 CG).

2/ Conocer en apelación de todas las impugnaciones en contra de las leyes objetadas de inconstitucionalidad en casos concretos, en cualquier juicio, en casación, o en los casos contemplados por la ley de la materia $\left(\operatorname{art}^{\mathrm{\rho}} 272, \mathrm{~d} / \mathrm{CG}\right)$.

c) Como órgano de control preventivo de la constitucionalidad la Corte asume las siguientes atribuciones:

1/ Emitir opinión sobre la constitucionalidad de los tratados, convenios y proyectos de

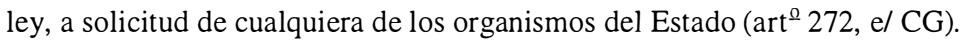

2/ Emitir opinión sobre la inconstitucionalidad de las leyes votadas por el Ejecutivo alegando inconstitucionalidad $\left(\operatorname{art}^{\complement} 272, \mathrm{~h} / \mathrm{CG}\right)$. 
3/ Dictaminar con carácter previo sobre la reforma de las leyes calificadas como constitucionales ( $\left.\operatorname{art}^{\circ} 175 \mathrm{CG}\right)$.

4/ Emitir dictamen previo favorable para que pueda ser reformada la Ley de Amparo, Exhibición Personal y de Constitucionalidad ( $\operatorname{art}^{ } 192$ LAEC).

5/ Emitir opinión consultiva que le fuere solicitada por el Congreso de la República, la Corte Suprema de Justicia o el Presidente de la República (artº 171 LAEC).

d) Otras competencias que la Constitución otorga a la Corte son:

1/ Una iniciativa política difícilmente justificable, a nuestro juicio, como es la iniciativa para proponer reformas a la Constitución ( $\operatorname{art}^{\mathrm{0}} 277, \mathrm{c} / \mathrm{CG}$ ).

2/ Una competencia orientada a la difusión y conocimiento de sus fallos, a la que se refiere el apartado g/ del $\operatorname{art}^{\underline{0}} 272$ de la Norma suprema, cual es la de compilar la doctrina y principios constitucionales que se vayan sentando con motivo de las resoluciones de amparo y de inconstitucionalidad de las leyes, manteniendo al día el boletín o gaceta jurisprudencial. $^{20}$

3/ Una competencia reglamentaria por cuanto que la Corte dispone de la facultad de dictar los reglamentos sobre su propia organización y funcionamiento, como asimismo de la potestad para emitir las disposiciones reglamentarias para suplir las situaciones no previstas en la ley de la materia, disposiciones que promulgará y publicará en el Diario Oficial.

\section{Legitimación procesal}

Están legitimados para plantear una acción directa de inconstitucionalidad contra una ley, reglamento o disposición de carácter general: la junta directiva del Colegio de Abogados a través de su Presidente; el Ministerio Público a través del Procurador General de la Nación; el Procurador de los Derechos Humanos, y, finalmente, cualquier persona con el auxilio de tres abogados colegiados activos.

En los casos concretos la persona a quien afecte directamente la inconstitucionalidad de una ley puede plantearla ante el tribunal que corresponda. El planteamiento lo podrán hacer las partes como excepción o en incidente de una ley que hubiere sido citada como apoyo de derecho en la demanda, en la contestación, o que de cualquier otro modo resulte del trámite del juicio.

20

Cfr. al efecto, Jorge Mario García Laguardia, El Tribunal Constitucional. Nueva Institución de la Constitución guatemalteca de 1985, en el colectivo, Memoria del III Congreso Iberoamericano de Derecho Constitucional, UNAM, México, 1987, tomo I, págs. 175-188. 
Como puede comprobarse, la legitimación es muy amplia, por lo menos si se compara con los supuestos de legitimación europeos. Aunque la legitimación se encomienda a una serie de instituciones y órganos constitucionales, coexiste con una auténtica acción popular de inconstitucionalidad. Si a ello se une la posibilidad de impugnar una ley en casos concretos, impugnación de la que conoce en primera instancia el tribunal ante quien se plantea, y de las apelaciones la Corte de Constitucionalidad, nos podemos dar una idea exacta de la extraordinaria amplitud con que se contempla la legitimación procesal.

\section{Efectos de las sentencias}

Una vez más hemos de diferenciar entre la inconstitucionalidad de las leyes, reglamentos y disposiciones de caráter general y la inconstitucionalidad de las leyes en casos contretos.

En el primer supuesto, cuando la sentencia, efectivamente, declare la inconstitucionalidad de la norma general impugnada, ésta quedará sin vigencia, y si la inconstitucionalidad fuere parcial, la norma quedará sin vigencia en la parte que se declare inconstitucional. Las sentencias de la Corte que declaren la inconstitucionalidad total o parcial deberán publicarse en el Diario Oficial dentro de los tres días siguientes a la fecha en que queden firmes. La norma general dejará de surtir efectos desde el día siguiente al de la publicación en el Diario Oficial.

En Guatemala, al igual que en Costa Rica, se ha previsto la posibilidad de que la interposición del recurso tenga efectos suspensivos sobre la norma impugnada. En efecto, la suspensión provisional procederá si a juicio de la Corte de Constitucionalidad "la inconstitucionalidad fuese notoria y susceptible de causar travámenes irreparables". En tal caso, la suspensión tendrá efecto general ( $\operatorname{art}^{\complement} 138$ LAEC). Pues bien, si se hubiese decretado la suspensión provisional (dentro de los ocho días siguientes a la interposición), los efectos del fallo definitivo se retrotraerán a la fecha en que se publicó la suspensión provisional.

Contra las sentencias de la Corte no cabrá recurso alguno, produciendo en estos casos efectos "erga omnes".

En el segundo caso (inconstitucionalidad de las leyes en casos concretos), los efectos de la declaración de inconstitucionalidad serán tan sólo para el caso concreto, produciendo respecto al mismo efectos de cosa juzgada. 


\section{Efectividad del control normativo de constitucionalidad}

Desde el inicio de sus funciones jurisdiccionales por la primera Corte de Constitucionalidad surgida al amparo de la Constitución de 1985, el día 9 de junio de 1986, la Corte ha desempeñado una encomiable labor, que ha tenido sus frutos en una lenta pero progresiva comprensión por parte de los poderes públicos y de sectores de la ciudadanía de que todo acto de autoridad ha de estar sujeto.a la observancia de la Norma suprema.

Sin ningún género de dudas, hay que reconocer que el momento culminante de la actuación de la Corte, que revela además una extraordinaria efectividad de su control normativo de constitucionalidad, lo encontramos en la sentencia por la que se declara la inconstitucionalidad del Decreto del Presidente Jorge Serrano Elías por el que se trataba de formalizar una suerte de "autogolpe de Estado". La sentencia de la Corte frustró tan flagrante vulneración constitucional, posibilitando a la postre el derrocamiento del aspirante a dictador.

La divulgación de las decisiones de la Corte a través de la llamada "Gaceta Jurisprudencial", una publicación trimestral en la que deben insertarse íntegramente todas las sentencias que dicte, las opiniones que evacúe de conformidad con la ley y los trabajos relacionados con asuntos jurídicos de su competencia que estime dignos de su publicación (además ya de que por mandato legal han de publicarse en el Diario Oficial los autos en que se declare la suspensión provisional de una ley, reglamento o disposición de carácter general y las sentencias en las que se declare la inconstitucionalidad de una norma general), ha venido a suponer un muy importante paso en orden a la difusión y estudio de una doctrina jurisprudencial avanzada y sensible hacia los grandes valores materiales de la Constitución y, muy singularmente, hacia los derechos constitucionales, con lo que ello a su vez está entrañando para la doctrina jurídica en general.

\section{Defensa de los Derechos Humanos}

\section{Antecedentes históricos y ordenación normativa actual}

La Constitución de la República Federal de Centroamérica de 1824 dedicaba su Título X a las "garantías de la libertad individual" ( $\operatorname{art}^{\circ} \mathrm{S} 152$ a 174), si bien, en realidad, con tal rótulo se refería a los derechos reconocidos por la Norma suprema. Entre las Leyes constitucionales de 1839, la tercera recibió le denominación de "Declaración de Derechos del Estado y sus Habitantes", siendo conocida como "Ley de Garantías". Su $\operatorname{art}^{\underline{0}} 8^{\underline{0}}$, de confusa redacción, determinaba que: Ni el Poder Constituyente, ni ninguna otra autoridad constituída tiene facultad para anular en la substancia, ni en sus efectos, los actos públicos o privados, efectuados en conformidad de una ley preceptiva o permisiva, vigente al tiempo de su verificación, o sin la prohibición de una ley preexistente; y cualquier ley o decretos es, ipso 
iure, nula y de ningún valor, como destructora de la estabilidad social, y atentatoria a los derechos de la comunidad y a los individuales".

La ausencia reiterada de unos mecanismos constitucionales de garantía de los derechos sería captada por los constituyentes de 1872, quienes en su "Proyecto de Constitución para la República de Guatemala, presentado a la Asamblea Constituyente el 20 de agosto de 1872 por la Comisión encargada de formarlo" llamaron la atención sobre el asunto.

El contraste es aún más chocante si se recuerda que el diputado suplente por Guatemala en las Cortes de Cádiz, don Manuel de Llano, en la sesión de esas Cortes del 14 de diciembre de 1810 pidió "que para precaver en parte los males que por tantos años han afligido a la nación, se nombre una comisión que exclusivamente se ocupe en redactar una ley al tenor de la del Habeas Corpus que rige en Inglaterra, que asegure la libertad individual de los ciudadanos" $^{21}$. Como al efecto advierte García Laguardia ${ }^{22}$, es el antecedente orgánico más antiguo del derecho constitucional centroamericano, y posiblemente en el hispanoamericano y español, del referido instituto procesal. El 15 de diciembre de 1810 se resolvía en las Cortes de Cádiz nombrar la Comisión instada por el diputado guatemalteco, y en la sesión de la mañana del día 17 se integraba una Comisión "para tratar la proposición hecha por el Sr. Llano relativa a la formación de un proyecto de ley que asegure la libertad individual de los ciudadanos".

Aunque la citada norma legal no fue aprobada nunca, la iniciativa tuvo amplio eco en Guatemala. Como recuerda García Laguardia ${ }^{23}$, cuando Bustamante y Guerra - precedido de fama de realista irreductible y duro en Montevideo - toma posesión de su cargo de Capitán General de Guatemala, el Ayuntamiento de Guatemala acusa recibo de su primer manifiesto haciendo una enérgica defensa de los principios constitucionales y llegando a afirmar que "uno de los diputados americanos ha tenido el honor de proponer a aquellas Cortes la ley de Habeas Corpus que ha sido aceptada, con lo que en lo de adelante se verá garantizada la seguridad personal".

Tras la independencia y como parte inicial del experimento liberal en las "Provincias Unidas de Centroamérica" se inició el primer intento de codificación que, en Guatemala, condujo a la adopción de los Códigos que Eduardo Livingston había formulado para el Estado Editorial Universitaria Centroamericana, $2^{\underline{a}}$ ed., San José (Costa Rica), 1976, pág. 198. 
de Louisiana. El $1^{1}$ de enero de 1837 se promulgaron los nuevos Códigos que entre las instituciones de mayor relevancia adoptaban el Habeas Corpus. ${ }^{24}$

El Código de Procedimientos para hacer efectivo el Código Penal del Estado de Guatemala, dedicaba el Capítulo sexto a la institución bajo el título de "la supresión de los delitos contra la libertad personal". A tenor de su $\operatorname{art}^{\circ}$ 56: "El remedio represivo de los delitos de la naturaleza indicada en la materia de este título (contra la libertad personal) es por el auto de exhibición de la persona". Y el artículo inmediatamente siguiente determinaba que: "Un auto de exhibición de la persona es una orden dada por escrito, expedida en nombre del Estado por juez o corte de jurisdicción competente, dirigida a cualquiera que tenga una persona en su custodia, o bajo su restricción, mandándole presentar aquella persona en cierto tiempo y lugar, y haciéndole manifestar la razón porque es tenido en custodia bajo restricción".

El naufragio del primer experimento liberal centroamericano no acabó, sin embargo, con el habeas corpus, que fue mantenido. Y la anteriormente referida "Ley de Garantías" de 1839 estableció en la sección segunda de su artº 19 que "ningún habitante del Estado puede ser ilegalmente detenido en prisión, y todos tienen derecho a ser presentados ante el juez competente, quien en el caso deberá dictar el auto de exhibición de la persona".

El reconocimiento y vigencia del habeas corpus contrasta con el olvido del amparo como mecanismo esencial de garantía de los derechos constitucionales.

El triunfo liberal de los inicios de la década de los setenta, que tuvo su reflejo constitucional en la Constitución de 1879 iba a incidir en el proceso que comentamos.

En lo que hace al habeas corpus, el $\operatorname{art}^{\underline{0}} 34$ de la citada Carta política previó que: "La Constitución reconoce el derecho de habeas corpus o sea la exhibición personal", y el Decreto Legislativo $\mathrm{n}^{\mathrm{Q}} 354$, de abril de 1897 , desarrolló la disposición constitucional, que protegía a las personas de la privación de libertad y del sufrimiento de "vejámenes o gravámenes no autorizados por la ley" y concedía a "cualquiera del pueblo" el derecho de pedir la libertad de los injustamente detenidos.

En lo que se refiere al amparo, el propio $\operatorname{art}^{\complement} 34$ estableció; "La Constitución reconoce el derecho de amparo. Una ley anexa desarrollará esa garantía". Como recuerda una vez más García Laguardia ${ }^{25}$, dos intentos de reconstrucción de la Federación Centroamericana abren el camino a la configuración del amparo en forma definitiva. El primero se produce

24

Cfr. al efecto, Jorge Mario García Laguardia, La defensa de la Constitución, op. cit., págs. 2832 .

Jorge Mario García Laguardia, La defensa de la Constitución, op. cit., pág. 39. 
en 1897, cuando se suscribe el "Tratado de Unión de Centroamérica". La Constituyente prevista en el Tratado se reunió en Honduras, promulgando la Constitución Política de los Estados Unidos de Centroamérica de 27 de agosto de $1898^{26}$. Dentro del Título III (relativo a los derechos civiles y garantías sociales) se insertaba un artículo (el $\operatorname{art}^{\mathrm{0}} 40$ ) a cuyo tenor: "Toda persona tiene derecho a pedir y obtener amparo contra cualquier autoridad o individuo que restrinja el ejercicio de los derechos individuales garantizados por la presente Constitución. Una ley especial reglamentará la manera de hacer efectivo este derecho". Y el $\operatorname{art}^{\circ} 145$ declaraba la Ley de Amparo como ley constitutiva, lo que, de conformidad con el precepto siguiente, significaba que la ley sólo podía "emitirse y reformarse por una Constituyente o por el Congreso Federal con los dos tercios de votos de cada Cámara".

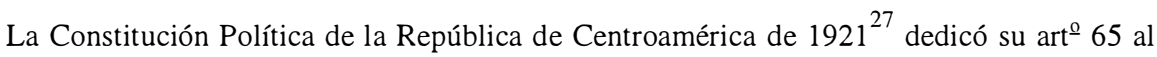
amparo. A tenor del mismo: "Contra la violación de las garantías constitucionales se establece el amparo. Una ley reglamentaria desarrollará este proyecto". La propia Asamblea Nacional Constituyente elaboró la Ley de Amparo, de 9 de septiembre de $1921^{28}$. La Ley, a juicio de García Laguardia ${ }^{29}$, fija las líneas históricas y doctrinales de evolución de la institución del amparo.

El $\operatorname{art}^{\underline{0}} 1^{\underline{\varrho}}$ de la citada norma legal disponía que toda persona tiene derecho a pedir amparo en los casos y para los efectos qui a continuación se expresaban: $1^{\underline{\varrho}}$ ) Para que se le mantenga o restituya en el goce y garantías que la Constitución establece. $2^{\underline{9}}$ ) Para que, en casos concretos, se declare que una ley, un reglamento o una disposición de la autoridad, no le es aplicable por ser inconstitucional. $3^{\underline{a}}$ ) Para su inmediata exhibición, cuando estuviere ilegalmente presa, detenida o cohibida de cualquier manera en el ejercicio de su libertad individual, o sufriere gravámenes indebidos, aunque la restricción fuere autorizada por la ley. $4^{\Omega}$ ) En los casos de altas militares e inscripciones ejecutadas ilegalmente.

Cuando el amparo tuviere por objeto reclamar por actos contra la persona o su libertad, se había de utilizar el recurso de habeas corpus o exhibición personal, objeto del Capítulo $3^{\text {}}$ de la Ley. En el caso de que fueren otros los derechos y garantías violados, se había de proceder en la forma prevista por el Capítulo $4^{\varrho}$, que procedía a normar el recurso de amparo.

Puede verse el texto de la Constitución en Ricardo Gallardo, Las Constituciones..., op. cit., vol. II, págs. 773 y sigs.

El text de la Constitución de 1921 puede verse en Ricardo Gallardo, Las Constituciones..., op. cit., págs. 809 y sigs.

El texto de la Ley de Amparo, en Ricardo Gallardo, Las Constituciones..., op. cit., págs. 866 y sigs.

29

Jorge Mario García Laguardia, La defensa de la Constitución, op. cit., pág. 40. 
El recurso de exhibición personal podía interponerlo el agraviado o cualquier otra persona, en su nombre, sin necesidad de poder, por escrito, verbalmente o por telégrafo. A su vez, el $\operatorname{art}^{\underline{0}} 6^{\underline{0}}$ de la Ley prescribía que siempre que la autoridad competente tuviere noticia de encontrarse ilegalmente detenida una persona, había de ordenar de oficio su exhibición personal.

Por su lado, la demanda de amparo tenía lugar contra cualquier autoridad o funcionario, bien obraran por sí o en cumplimiento de una ley o de orden de un superior; podía interponerse por la persona agraviada o por su representante legal.

Las reformas constitucionales de 1927 mantendrían la configuración preexistente del amparo con la novedad añadida de la constitucionalización de algunas de las disposiciones de la Ley de 1921. El $\operatorname{art}^{\circ} 2^{\underline{\varrho}}$ de las Disposiciones transitorias de esta reforma ordenó que la Asamblea Legislativa aprobara una Ley de Amparo, norma aprobada por el Decreto Legislativo número 1529, de 12 mayo de 1928, cuya dilatada vigencia superaría a la del propio texto constitucional. La Ley reguló el amparo, el habeas corpus y el recurso orientado a que, en casos contretos, se declarara que una ley, un reglamento o cualquier disposición de la autoridad no era aplicable al recurrente por su vulneración de la Constitución.

La Constitución de 1945, que fijó las bases del constitucionalismo social en Guatemala, desarrolló los principios del amparo, ampliando su regulación. Es de subrayar que declaró la nulidad "ipso iure" de las disposiciones legales, gubernativas o de cualquier otro orden que regularan el ejercicio de los derechos que garantizaba la Constitución, si los disminuían, restringían o tergiversaban, así como la de aquellos actos o contratos que violaran las normas constitucionales.

La Constitución contempló tres supuestos diferenciados de protección a través del amparo: en los casos y para los efectos qui a continuación se expresaban: $1^{\stackrel{\rho}{ })}$ Como recurso contra todas las autoridades a efectos de que se mantuviera o restituyera a la persona en el goce de los derechos y garantías que la Constitución reconoce. $2^{\underline{Q}}$ ) Como recurso para que, en casos concretos, se declarara que una ley, un reglamento o cualquier disposición de la autoridad no era aplicable a la persona recurrente. En este supuesto, el amparo actuaba como una suerte de recurso contra actos legislativos, esto es, como amparo frente a leyes inconstitucionales. Como recuerda García Laguardia nuevamente ${ }^{30}$, la interpretación que pareció consolidarse como más adecuada era la de que la institución del amparo se refería en este caso a las llamadas leyes autoaplicativas, esto es, aquellas cuya sola promulgación afectaba a los destinatarios. $3^{\underline{0}}$ ) Como recurso de habeas corpus. 
Tras diversas vicisitudes constitucionales, la Constitución de 1956 prestó una especialísima atención a los derechos humanos y a las garantías individuales. Su $\operatorname{art}^{\varrho} 79$ determinó el objeto del amparo en estos términos: "El amparo tiene como función esencial el mantenimiento de las garantías individuales y la invulnerabilidad de los preceptos de la Constitución".

La suspensión de la vigencia de la Constitución de 1956, a consecuencia del golpe de Estado de 1963, y la subsiguiente promulgación de una llamada "Carta Fundamental del Gobierno", que no reconocía el amparo, aunque sí el habeas corpus, serían los antecedentes inmediatos de la Constitución de 1965, que no sólo reguló en detalle las garantías constitucionales, sino que, como ya señalamos, creó una Corte de Constitucionalidad, además ya de los Tribunales de Amparo. La propia Asamblea Constituyente aprobaría mediante su Decreto número 8 la Ley de Amparo, Habeas Corpus y de Constitucionalidad, que vendría a desarrollar los principios constitucionales.

El amparo fue concebido por la nueva Constitución con la finalidad de otorgar protección a los particulares contra la violación de los derechos consignados en ella con ocasión de actos de los organismos públicos y en algunos casos de particulares. Asimismo, se diseñó como un medio de control de constitucionalidad de leyes en casos concretos, por contravención o restricción de cualesquiera de los derechos constitucionalmente garantizados.

La competencia para conocer del amparo recayó en los mismos tribunales de la jurisdicción ordinaria, bien que constituídos en Tribunales de Amparo, con atribuciones especiales por lo que constituían una jurisdicción privativa. La Constitución creó asimismo un Tribunal Extraordinario de Amparo, al que correspondía conocer de los recursos procedentes contra la Corte Suprema o cualquiera de sus miembros y contra el Congreso de la República y el Consejo de Estado por actos o resoluciones no meramente legislativas. Este Tribunal se integraba por el Presidente de la Sala Primera de la Corte de Apelaciones o, en su defecto, por el de las otras, en orden numérico, y por seis vocales de las propias Salas, designados por sorteo entre los propietarios y suplentes de las mismas.

En cuanto al Habeas Corpus, la Constitución de 1965 mantendría inalterada la institución, que sería desarrollada, como ya señalamos, por el citado Decreto núm. 8 de la Asamblea Constituyente. 


\section{Instrumentos procesales protectores: Amparo y Habeas Corpus}

\section{a) Su configuración jurídica actual}

La vigente Constitución Política de Guatemala, de 1985, instituye el amparo en su $\operatorname{art}^{\circ} \mathbf{2} 265$, "con el fin de proteger a las personas contra las amenazas de violaciones a sus derechos o para restaurar el imperio de los mismos cuando la violación hubiere ocurrido".

A su vez, el $\operatorname{art}^{\underline{0}} 272$, en su apartado b/, otorga a la Corte de Constitucionalidad, tal y como ya señaláramos, la competencia para conocer en única instancia, en calidad de Tribunal Extraordinario de Amparo, en las acciones de amparo interpuestas en contra del Congreso de la República, la Corte Suprema de Justicia, el Presidente y el Vicepresidente de la República. Y en su apartado c/, el propio precepto le atribuye el conocimiento en apelación de todos los amparos interpuestos ante cualesquiera de los tribunales de justicia.

Finalmente, también como ya advirtiéramos, el $\operatorname{art}^{\stackrel{0}{ }} 276$ se remite a una ley constitucional a los efectos del desarrollo de la materia relativa al amparo, a la exhibición personal y a la constitucionalidad de las leyes, ley que, como ya se ha expuesto, fue aprobada por el Decreto núm. 1/86 emitido por la Asamblea Nacional Constituyente: Ley de Amparo, Exhibición Personal y de Constitucionalidad (LAEC).

\section{b) Derechos protegidos}

El art $^{\underline{0}} 265$ de la Constitución, en sintonía con lo que constituye un común denominador del amparo en Centroamérica, determina que procede el amparo frente a aquellos actos de autoridad que lleven implícitos "una amenaza, restricción o violación a los derechos que la Constitución y las leyes garantizan". La amplitud de los derechos protegidos contrasta pues, con aquellos otros ordenamientos, como el alemán o el español, que circunscriben la protección conferida a través del amparo a un núcleo de derechos considerados como "fundamentales".

A su vez, y en desarrollo de la previsión constitucional, el $\operatorname{art}^{\underline{0}} 1^{\underline{0}}$ de la LAEC todavía amplía más si cabe esta protección, al extender la misma a los "derechos inherentes a la persona protegida por la Constitución Política de la República de Guatemala, las leyes y los convenios ratificados por Guatemala". 
Como bien ha significao López Guerra ${ }^{31}$, este tipo de declaraciones reviste extraordinaria importancia, máxime si en los convenios internacionales sobre derechos humanos se prevé un órgano jurisdiccional específico para su aplicación e interpretación, por cuanto entonces la interpretación y jurisprudencia de tales órganos inter o supranacionales se convertirá así en vinculante para los órganos jurisdiccionales nacionales, creándose un patrón generalizado de protección de esos derechos.

Conviene señalar que el amparo no rige para la protección de la libertad personal, por cuanto la garantía de este derecho se canaliza a través del recurso de habeas corpus o exhibición personal.

En resumen, el ámbito de los derechos protegidos es en Guatemala excepcionalmente amplio, circunstancia que encuentra su complemento natural en la redacción del $\operatorname{art}^{\complement} 265$ de la Norma suprema, cuyo inciso segundo se abre con esta afirmación: "No hay ámbito que no sea susceptible de amparo", previsión que alude ya al tipo de actos frente a los que cabe el amparo.

\section{c) Eficacia del amparo: frente a poderes públicos y particulares}

La tendencia inmediatamente antes referida a maximizar el ámbito de los derechos protegidos encuentra su reflejo más nítido en esa determinación constitucional del $\operatorname{art}^{\underline{0}} 265$ en el sentido de que "no hay ámbito que no sea susceptible de amparo", previsión que se complementa con la inmediatamente ulterior de que el amparo procederá "siempre que los actos, resoluciones, disposiciones o leyes de autoridad lleven implícitos una amenaza, restricción o violación a los derechos" garantizados constitucional, legal o convencionalmente.

La determinación constitucional ya nos revela que el amparo, frente a lo que constituye la pauta general, no es un remedio frente a actuaciones tan sólo procedentes del poder ejecutivo, sino que también se contempla el "amparo frente a leyes".

Aunque, como se ha señalado ${ }^{32}$, la existencia de un control normativo difuso - contemplado, recordémoslo, por el $\operatorname{art}^{\complement} 266$ de la Constitución, que se refiere a la inconstitucionalidad de las leyes en casos concretos - hace cuestionable la autonomía de un "amparo contra leyes", lo cierto es que tanto el $\operatorname{art}^{\varrho} 265$ de la Constitución como el $\operatorname{art}^{\varrho} 8^{\varrho}$ de la LAEC prevén de modo inequívoco la posibilidad de un amparo de esta naturaleza. En

31 Luis López. Guerra, Protección de los derechos fundamentales por la jurisdicción constitucional 32 en Centroamérica y Panamá, op. cit., pág. 103.

Ibídem, pág. 104. 
efecto, mientras este último precepto reitera la dicción constitucional del $\operatorname{art}^{\stackrel{\varrho}{ }} 265$, el $\operatorname{art}^{\mathrm{\varrho}} 10$ de la LAEC prevé que toda persona tiene derecho a pedir amparo, entre otros casos, y según su apartado b/, para que se declare en casos contretos que una ley, un reglamento, una resolución o acto de autoridad no obligan al recurrente por contravenir o restringir cualesquiera de los derechos garantizados por la Constitución o reconocidos por cualquier otra ley.

En todo caso, la diferencia entre el amparo contra leyes a que se refieren los citados preceptos y la acción de inconstitucionalidad contra leyes en casos contretos a que alude el $\operatorname{art}^{\underline{ }}$ 266 de la Constitución y que desarrolla el art ${ }^{\underline{0}} 116$ de la LAEC, no parece nada clara, pues, además, en ambos supuestos hay que presuponer que nos hallamos ante una ley autoaplicativa, tal y como entendió García Laguardia ${ }^{33}$ al interpretar una previsión análoga de la Constitución de 1945.

Por lo demás, es evidente a la vista de las respectivas normas constitucionales y legales, que mientras la inconstitucionalidad a que se refiere el art $^{\circledR} 266$ de la Constitución sólo cabe contra leyes, el amparo previsto por el $\operatorname{art}^{\circ} 265$ y desarrollado por el $\operatorname{art}^{\circ} 10$, b/ de la LAEC cabe frente a leyes, reglamentos, resoluciones o actos de autoridad en general.

Como es lógico, es frente a actuaciones del ejecutivo o de la administración pública donde el amparo muestra una mayor vivacidad, lo que se explica por la histórica aparición del ejecutivo y sus agentes como los mayores agresores de los derechos constitucionales. Además, las actuaciones administrativas desencadenan las mayores amenazas potenciales para los derechos por la tradicional ejecutoriedad de los actos administrativos y la capacidad de autotutela de la administración.

Sin embargo, como bien apunta López Guerra ${ }^{34}$, debe tenerse en cuenta en este punto el desarrollo cada vez mayor de la jurisdicción contencioso-administrativa comi vía de protección frente a los abusos de la administración y la vulneración de derechos de los cuidadanos. Buen ejemplo de este desarrollo lo encontramos en la propia Constitución guatemalteca, cuyo $\operatorname{art}^{\underline{0}} 221$ crea el Tribunal de lo Contencioso-Administrativo, cuya función es la de "contralor de la juridicidad de la administración pública", disponiendo de atribuciones para conocer en caso de contienda por actos o resoluciones de la administración y de la entidades descentralizadas y autónomas del Estado, así como en los casos de controversias derivadas de contratos y concesiones administrativas". Contra sus resoluciones y autos que pongan fin al proceso podrá interponerse el recurso de casación.

Luis López Guerra, Protección de los derechos fundamentales..., op. cit., pág. 105. 
La existencia de esta jurisdicción contencioso-administrativa plantea, con carácter general, la problemática de la posible duplicidad de vías de protección de los derechos: la vía contencioso-administrativa y la vía del amparo. Sin embargo, esta problemática queda resuelta en cuanto que la petición de amparo en asuntos administrativos exige del agotamiento previo de los recursos ordinarios; esto es, el amparo se concibe como una vía subsidiaria por lo que debe entenderse que no cabrá su interposición hasta tanto se haya agotado la vía contencioso-administrativa.

A diferencia de otros países centroamericanos, cual es el caso de Costa Rica y Nicaragua, el amparo guatemalteco cabe frente a actuaciones de orden jurisdiccional. El $\operatorname{art}^{\varrho} 265$ de la Norma suprema sienta las pautas para la admisibilidad del amparo en estos casos al proclamar que "no hay ámbito que no sea susceptible de amparo". Y el apartado b/ del artํํ 272 corrobora la anterior apreciación al prever acciones de amparo interpuestas en contra de la Corte Suprema de Justicia, de las que, como ya vimos, conoce en única instancia y en calidad de Tribunal Extraordinario de Amparo, la Corte de Constitucionalidad.

Una última cuestión cabe plantearse: ¿cabe el amparo frente a particulares? El ordenamiento guatemalteco se alinea en este punto con los más avanzados (como el colombiano o el costarricense) al establecer el $\operatorname{art}^{\underline{0}} 9^{\varrho}$ de la LAEC la procedencia del amparo "contra entidades a las que debe ingresarse por mandato legal y otras reconocidas por la ley, tales como partidos políticos, asociaciones, sociedades, sindicatos, cooperativas y otras semejantes". La fórmula legal se nos antoja muy positiva por cuanto toda relación entre un ciudadano particular y esas entidades es más que probable que esté asentada en la disparidad de posiciones, esto es, en una relación de superioridad-inferioridad que excluye la autonomía de la voluntad como causa justificativa de una posible restricción de derechos y, por lo mismo, de una exclusión de la vía del amparo para la tutela del derecho conculcado, por cuanto que la autonomía de la voluntad tan sólo puede existir cuando las relaciones están asentadas en una paridad de posiciones.

Por lo que se refiere al habeas corpus, conviene significar que el ordenamiento guatemalteco parece configurarlo como un instrumento procesal de garantía frente a actuaciones del ejecutivo o sus agentes. En efecto, el $\operatorname{art}^{\underline{0}} 82$ de la LAEC conforma esta garantía como el derecho a pedir la inmediata exhibición ante los tribunales de justicia por parte de quien se encuentre preso, detenido o cohibido de cualquier modo en el goce de su libertad individual o amenazado de la pérdida de ella.

Hemos de reseñar finalmente que tanto el amparo como el habeas corpus se nos presentan como mecanismos procesales de garantía constitucional que tratan de hacer frente no sólo a las violaciones efectivas de derechos, sino a las amenazas potenciales a los mismos; ello entraña que nos hallemos en presencia de instrumentos no sólo represivos, por así llamarlos, sino también preventivos. 
El $\operatorname{art}^{\circledR} 265$ de la Constitución, como ya señalamos, instutuye el amparo con la finalidad de proteger a las personas, entre otros atentados a los derechos, "contra las amenazas de violaciones a sus derechos". Y el $\operatorname{art}^{\underline{0}} 82$ de la LAEC se refiere igualmente a las amenazas de pérdida de la libertad individual. Parece razonable entender que esa amenaza habrá de ser real y presuponer una posible e inmediata vulneración del derecho de que se trate.

\section{d) Legitimación procesal. Sus requisitos}

Está legitimado para solicitar el amparo la persona directamente afectada, por lo que, como señala Gonzáles Rodas ${ }^{35}$, debe existir una relación directa entre la autoridad, el acto reclamado, la violación, el agravio causado y el agraviado.

El amparo debe solicitarse por escrito, cumplimentando los requisitos formales que la LAEC restablece, en el bien entendido de que la omisión de alguno de ellos podrá ser subsanada en el término de tres días.

El amparo ha de pedirse dentro del plazo de los treinta días siguientes al de la última notificación al afectado o de conocido por éste el hecho que le agravie o viole alguno de sus derechos.

Por lo que al habeas corpus se refiere, se configura como un derecho del afectado, por lo que estará legitimado para recurrir a este instrumento de garantía quien se encuentre preso, detenido o afectado de cualquier modo en el goce de su libertad individual, amenazado de la pérdida de ella o, aún cuando su prisión o detención fuere fundada en la ley, se encontrare sometido a vejámenes. Bien es verdad que junto a esa concepción subjetivista, se posibilita la interposición de un habeas corpus por cualquier otra persona distinta del directamente afectado en su derecho a la libertad personal, sin sujeción a requisitos de ninguna clase.

\section{e) Organos competentes}

La competencia para conocer del amparo en primera instancia se distribuye, según los sujetos pasivos, entre la Corte Suprema de Justicia y los restantes tribunales ordinarios.

Como ya hemos tenido oportunidad de señalar, la Corte de Constitucionalidad sólo conoce de los recursos de amparo por apelación de las sentencias, cuando el amparo haya sodi interpuesto ante cualquier tribunal de justicia. A su vez, como también se ha señalado, 
conoce en primera y única instancia de los amparos interpuestos contra el Congreso de la República, la Corte Suprema de Justicia, el Presidente y el Vicepresidente de la República. En estos casos la Corte de Constitucionalidad conoce en calidad de Tribunal Extraordinario de Amparo.

El ordenamiento guatemalteco no prevé un trámite especívico de admisión que atienda a la efectiva viabilidad, por razones de fondo, del amparo planteado, a fin de evitar que esta vía pueda ser utilizada con una finalidad dilatoria o fraudulenta. En consecuencia, no se establece un filtro previo análogo al "writ of certiorari" norteamericano o al "Nichtannahmeverfahren" (procedimiento de no admisión) del Tribunal Constitucional Federal alemán. Como bien señala López Guerra ${ }^{36}$, esta ausencia puede resultar disfunctional, si se tiene en cuenta que la mera admisión de un amparo puede tener consecuencias jurídicas de importancia, sobre todo la suspensión de la efectividad del acto recurrido.

La LAEC, bajo el enunciado de "amparo provisional", enumera los supuestos en que procede la suspensión de oficio, además de aquellos otros en que procede a petición del interesado ( $\left.\operatorname{art}^{\underline{0}} 28 \mathrm{LAEC}\right)$.

Por lo que se refiere al habeas corpus, la competencia se residencia en varios niveles jurisdiccionales.

El énfasis se pone en todo caso en la exhibición personal, esto es, en la constancia de la detención, presencia y estado físico del afectado. Y así, el $\operatorname{art}^{\underline{0}} 95$ de la LAEC determina que cuando la exhibición se hubiere solicitado en favor de personas plagiadas o desaparecidas, el Juez que haya ordenado la exhibición debe comparecer por sí mismo a buscarlas en el lugar en donde presuntamente se encuentren, ya sean centros de detención, cárceles o cualquier otro lugar señalado, sugerido o sospechado en donde pudieran encontrarse.

En cuanto que la eficacia del procedimiento de habeas corpus depende en gran parte del cumplimiento, por parte de la autoridad o particular a quien se intima la exhibición personal del afectado, o que informa sobre la situación personal del mismo, del mandato del juez o tribunal en este sentido, la legislación guatemalteca concede una extraordinaria importancia a la penalización de las conductas obstructivas o impeditivas del habeas corpus. De esta forma, el $\operatorname{art}^{\complement} 108$ de la LAED determina que: "Las autoridades que ordenaren el ocultamiento del detenido, o se hegaren a presentarlo al Tribunal respectivo, o que en cualquier otra forma burlaren la garantía de la exhibición personal, así como los agentes ejecutores, incurrirán en el delito de plagio, serán separados de sus cargos y cancionados de conformidad con la ley". 


\section{f) Efectos de las sentencias. Recursos}

Las resoluciones en procesos de amparo no causan excepcion de cosa juzgada, pero la interpretación de las normas de la Constitución y otras leyes contenidas en las sentencias de la Corte de Constitucionalidad, sientan doctrina legal a llegar a los tres fallos análogos de la misma Corte, doctrina que ha de ser respetada por los tribunales ordinarios.

En cuanto que el amparo, como regla general, debe pedirse por la persona directamente afectada, su efecto es dejar en suspenso respecto al reclamante el acto reclamado y restablecerlo en la situación jurídica afectada.

En cuanto atañe al habeas corpus, cabe decir que una vez localizado el afectado y verificada la causa de su detención, procede que el órgano jurisdiccional se pronuncie sobre la legitimidad o ilegitimidad de ésta, si bien, como se ha advertico ${ }^{37}$, éste es el aspecto menos relevante del procedimiento, al menos desde la perspectiva tradicional. El objeto del procedimiento es que el poder judicial conozca de la privación de libertad, así como de la integridad física del detenido; por decirlo así, se trata en garantía de la libertad, vida e integridad del individuo, de introducir su situación personal dentro del ámbito del poder judicial, que es quien mejor podrá proteger esos derechos frente al ejecutivo. Una vez que el poder judicial haya obtenido la exhibición personal del detenido lo que procederá es decidir sobre la causa de la detención, analizando su legitimidad o falta de ella, y decidiendo en consecuencia.

De las sentencias dictadas en un recurso de amparo interpuesto ante un tribunal de justicia, conoce en apelación, como ya hemos subrayado en varias ocasiones, la Corte de Constitucionalidad.

37 Ibídem, págs. 115-116. 
vival by covering themselves of the support of important interest groups and at the same time of deterring others from taking over power.

Personalization of political decisions and politicization of economy and administration as well as personalization and privatization of the juridical sector are necessary political elements to maintain power in authoritarian regimes leading all to and requiring widespread juridical insecurity. As economic and political development can hardly be expected in such authoritarian regimes, the introduction of more democratic and constitution based elements and the implementation of market economic structures are necessary.

\title{
Constitutional Jurisdiction in Guatemala
}

\author{
By Francisco Fernández Segado
}

In Guatemala, the peace treaty signed on December 29, 1996 by President Alvaro Arzú, heading the peace-commission COPAZ, and by the leaders of the URNG, merging four major guerilla-groups, ended a six-year peace marathon which followed 36 years of armed conflict, the last contemporary armed conflict to be solved in Central America.

Nevertheless, 12 years ago, on July 1, 1984, general, fair and free elections for a constitutional assembly took place. This constituante managed to draw up a new constitution within 10 months, which was then promulgated on May 31, 1985. The paper focuses on the newly created constitutional court of Guatemala and, in comparison with the preceding constitution of 1966, on the legal framework attributing this court the powers to protect both human rights and the constitutionality of the political process in general.

The author gives an extensive overview which may serve as a solid base for the upcoming discussion, whether or not democratically legitimated constitutional jurisprudence is able to play an important role in enforcing the peace treaty implementation process within the country.

\section{Popular Action in defense of "Divine Law": Hisba in contemporary Egypt}

\section{By Kilian Bälz}

The paper investigates the Islamic principle of hisba in contemporary Egypt. In examining recent Egyptian case-law, the paper argues that the traditional concept of hisba, the Islamic duty to "promote good and prevent evil", underwent a fundamental transformation: traditionally, the duty of hisba rested upon the public function of the muhtasib ["market supervisor"]. Today, in contrast, the principle is employed to entitle a third party to an action in 